\title{
ANALISIS KINERJA KEUANGAN PADA PT. BANK MANDIRI (PERSERO) TBK
}

\author{
Krisniawati $^{1}$ Muhammad Zulkarnain ${ }^{2}$ \\ Marliansyah Putra ${ }^{3}$
}

\begin{abstract}
Abstrak
Penelitian ini dilakukan dengan tujuan untuk menganalisis kinerja keuangan PT. Bank Mandiri (Persero) Tbk. Penelitian ini menggunakan data skunder yang bersumber dari website The Indonesia Capital Market Institute berupa laporan tahunan PT. Bank Mandiri (Persero)Tbk pada tahun 2011-2015. Data dianalisis dengan menggunakan pengukuran kinerja keuangan berdasarkan analisis rasio Return on Asset (ROA) dan rasio Capital Asset Manajemen Earning Likuidity (CAMEL) yang terdiri dari Capital Adequecy Ratio (CAR), Rasio Aktiva produktif (KAP), rasio Net Profit Margin (NPM), rasio Beban Operasi Pendapatan Operasi (BOPO) dan Loan to Deposit Ratio (LDR). Hasil penelitian diperoleh bahwa kinerja keuangan berdasarkan rasio Return on Asset (ROA) pada PT. Bank Mandiri (Persero)Tbk dikategorikan SEHAT dengan rata-rata nilai $R O A$ sebesar 3,46\% dari ketetapan standard kinerja keuangan sebesar 1,215\%. Berdasarkan analisis CAMEL untuk rasio CAR, KAP, NPM, BOPO, LDR dikategorikan kinerja keuangan bank SEHAT.
\end{abstract}

Kata Kunci : Kinerja Keuangan, ROA, CAMEL

\begin{abstract}
This research was conducted with the aim to analyze the financial performance of PT. Bank Mandiri (Persero) Tbk ... This study uses secondary data sourced from the website of The Indonesia Capital Market Institute in the form of an annual report of PT. Bank Mandiri (Persero) Tbk in 2011-2015. Data were analyzed using financial performance measurements based on analysis of the Return on Assets (ROA) ratio and the Capital Asset Management Earning Liquidity (CAMEL) ratio consisting of Capital Adequecy Ratio (CAR), Productive Asset Ratio (KAP), Net Profit Margin (NPM) ratio, the ratio of Operating Expenses to Operating Income (BOPO) and Loan to Deposit Ratio (LDR). The results showed that the financial performance based on the ratio of Return on Assets (ROA) at PT. Bank Mandiri (Persero) Tbk is categorized HEALTHY with an average $R O A$ value of $3.46 \%$ from the provision of financial performance standards of $1.215 \%$. Based on CAMEL analysis for CAR, KAP, NPM, BOPO, and LDR ratios, the financial performance of the bank is HEALTHY.
\end{abstract}

Keywords: Financial Performance, ROA, CAMEL

1, 2, 3 Dosen STIM Pase Langsa, e-mail: krisniawati2892@gmail.com 


\section{PENDAHULUAN}

Perekonomian Indonesia yang telah mengalami penurunan pada masa krisis ekonomi 1998 yang dikenal secara umum dengan sebutan krisis moneter memberikan dampak negatif untuk kegiatan sektor keuangan dan perbankan. Keterpurukan sektor perbankan di Indonesia pada mulanya adalah krisis nilai tukar terhadap sektor perbankan yang disebabkan karena adanya penyimpangan dan kelemahan pada beberapa sektor perbankan, diantaranya adalah banyak bank yang melakukan pinjaman ke luar negeri tanpa melakukan strategi trading untuk melindungi dana trader dari fluktuasi nilai tukar mata uang yang tidak menguntungkan (hedging).

Keberhasilan perekonomian di Indonesia tidak terlepas dari sektor perbankan, khususnya peran perbankan sebagai sumber pembiayaan industry dalam negeri. Keberhasilan perbaikan perekonomian ini memberikan dampak kepada persaingan dalam usaha perbankan sehingga para pelaku perbankan mempunyai kepentingan dalam hal pengambilan keputusan untuk bisa meningkatkan kinerja keuangan. Kinerja keuangan dapat dilihat dari laporan keuangan yang dimiliki oleh perusahaan perbankan yang bersangkutan yaitu tercermin dari informasi yang diperoleh pada neraca, laporan laba rugi dan laporan arus kas serta hal-hal yang mendukung penguatan penilaian kinerja keuangan.

PT. Bank Mandiri (Persero), Tbk. merupakan salah satu bank pemerintah yang terdaftar pada Bursa Efek Indonesia (BEI). Sebagai bank pemerintah yang menjadi tonggak perekonomian, PT. Bank Mandiri (Persero) Tbk. beroperasi atas dasar kepercayaan masyarakat yang dijadikan sebagai asset terpenting, sehingga bank harus bisa menunjukkan dan membuktikan kinerja yang baik untuk bisa terus menjaga dan memperoleh kepercayaan tersebut. Pengukuran kinerja keuangan pada bank harus terus dilakukan setiap tahunnya agar dapat terdeteksi terjadinya penurunan kinerja keuangan mengarah pada kategori yang tidak sehat, seperti menurunnya pendapatan, besarnya kredit yang tidak kembali, meningkatnya kredit yang bermasalah, sehingga harus cepat diatasi dengan modal (capital) yang dimiliki.

Berdasarkan data laporan keuangan yang diperolah dari idx.co.id (2016), pada tahun 2011 sampai dengan 2014 terjadi kenaikan pendapatan bank, namun pada tahun 2015 mengalami penurunan pendapaatan dari 21.482.880 triliun menjadi 20.448.829 triliun. Selanjutnya berdasarkan data yang diperoleh dari bisnis.com, pada tahun 2014 terjadi peningkatan kredit bermasalah ( Non Performing Loan) dari tahun sebelumnya sebesar $0,57 \%$ meningkat menjadi $0,67 \%$. Secara umum terjadinya peningkatan kredit bermasalah disebabkan keadaan perekonomian serta lemahnya pengawasan pihak bank dalam menganalisa kredit yang diberikan kepada kreditor.

Penelitian ini dilakukan bertujuan untuk mengetahui kinerja keuangan PT. Bank 
Mandiri (Persero)Tbk pada tahun 2011 - 2015 berdasarkan rasio profitabilitas berupa Return On Asset (ROA) dan pedekatan Capital, Asset, Management, Earning dan Liqudity (CAMEL)

\section{TINJAUAN PUSTAKA}

\subsection{Kinerja Keuangan}

Menurut Fahmi (2011:2) kinerja keuangan adalah suatu analisis yang dilakukan untuk melihat sejauh mana suatu perusahaan telah melaksanakan dengan menggunakan aturan-aturan keuangan secara baik dan benar. Sedangkan menurut Jumingan (2011:239) menyatakan bahwa kinerja keuangan merupakan gambaran kondisi keuangan bank pada suatu periode tertentu baik menyangkut aspek penghimpunan dana maupun penyakuran dana yang biasanya diukur dengan indikator kecukupan modal, likuiditas dan profitabilitas bank.

\subsubsection{Tahap-Tahap Menganalisis Kinerja Keuangan}

Fahmi (2011:240) terdapat 5 (lima) tahap dalam menganalisis kinerja keuangan yaitu:

1). Melakukan riview terhadap data laporan keuangan

Review disini melakukan dengan tujuan agar laporan keuangan yang sudah ada dibuat tersebut sesuai dengan penerapan kaidah-kaidah yang berlaku umum dalam dunia akuntansi, sehingga dengan demikian hasil laporan keuangan tersebut dapat dipertanggung jawabkan

2). Melakukan perhitungan

Penerapan metode perhitungan disini adalah disesuaikan dengan kondisi dan permasalahan yang sedang dilakukan sehingga hasil dari perhitungan tersebut akan memberikan kesimpulan sesuai dengan analisis yang diinginkan

3). Melakukan perbandingan terhadap hasil hitungan yang telah diperoleh Metode ini yang paling umum dipergunakan, untuk melakukan perbandingan ini ada dua, yaitu:

a. Time series analysis, yaitu membandingkan secara antar waktu atau periode, dengan tujuan itu nantinya akan terlihat secara grafik.

b. Cross Sectional Approach, yaitu melakukan perbandingan terhadap hasil hitungan rasio-rasio yang telah dilakukan antara suatu perusahaan dan perusahaan lainnya dalam ruang lingkup yang sejenis yang dilakukan secara bersamaan.

4. Melakukan penafsiran (interpretation) terhadap berbagai permasalahan yang 
ditemukan.

Pada tahap ini analisis melihat kinerja keuangan perusahaan adalah setelah dilakukan ketiga tahap tersebut baru selanjutnya dilakukan penafsiran untuk melihat apa-apa saja permasalahan dan kendala-kendala yang dialami oleh perusahaan tersebut.

5. Mencari dan memberikan pemecahan masalah (solution) terhadap permasalahan yang ditemukan.

Pada tahap terakhir ini ditemukan berbagai permasalahan yang dihadapi maka dicarikan solusi guna memberikan suatu input atau masukan agar apa yang menjadi kendala dan hambatan selama ini dapat terselesaikan.

\subsubsection{Pengukuran Kinerja Keuangan}

Menurut Syamsuddin (2009:74), Return on Asset (ROA) digunakan untuk mengukur kemampuan manajemen bank dalam memperoleh keuntungan (laba) secara keseluruhan. Semakin besar ROA suatu bank, maka semakin besar pula tingkat keuntungan yang dicapai bank tersebut dan semakin baik pulabank tersebut dari segi penggunaan asset. Sedangkan menurut Kasmir (2011:201) Return On Asset (ROA) merupakan rasio menunjukkan hasil atas jumlah aktiva yang digunakan dalam perusahaan. ROA juga merupakan suatu ukuran tentang efektivitas manajemen dalam mengelola investasinya. Hasil pengembalian investasi menunjukkan produktivitas dari seluruh dana perusahaan, baik modal pinjaman maupun modal sendiri. Semakin kecil resiko ini, semakin baik, demikian pula sebaliknya. Artinya rasio ini digunakan untuk mengukur efektivitas dari keseluruhan operasi perusahaan.

ROA dirumuskan sebagai berikut:

$$
\text { Return On Asset }(R O A)=\frac{\text { Earning After Interest and Tax }}{\text { Total Asset }}
$$

Kriteria penilaian ROA (Return On Asset):

\begin{tabular}{cc}
\hline Nilai Kredit & Predikat \\
\hline$\geq 1,215 \%$ & Sehat \\
$\geq 0,999-<1,215 \%$ & Cukup Sehat \\
$\geq 0,765-<0,999 \%$ & Kurang Sehat \\
$<0,765 \%$ & Tidak Sehat \\
\hline
\end{tabular}

Berdasarkan Surat Edaran Bank Indonesia N0.6/23/DPNP Jakarta tanggal 31 Mei 2004, menyebutkan aspek melalui rasio CAMEL adalah sebagai berikut: 


\section{Permodalan (Capital)}

Penilaian dilakukan terhadap komponen sebagai berikut:

a. Kecukupan pemenuhan Kewajiban Penyediaan Modal Minimum (KPMM) terhadap ketentuan yang berlaku.

b. Komposisi permodalan

c. Trend ke depan/ proyeksi KPMM

d. Aktiva produktif yang diklasifikasikan dibandingkan dengan modal bank

e. Kemampuan bank memelihara kebutuhan penambahan modal yang berasal dari keuntungan (laba ditahan).

f. Rencana permodalan bank untuk mendukung pertumbuhan usaha

g. Akses kepada sumber permodalan

h. Kinerja keuangan pemegang saham untuk meningkatkan permodalan bank.

2. Kualitas Aset (Asset Quality)

Penilaian dilakukan terhadap komponen sebagai berikut:

a. Aktiva produktif yang diklasifikasikan dibandingkan dengan total aktiva produktif

b. Debitur inti kredit di luar pihak terkait dibandingkan dengan total kredit

c. Perkembangan aktiva produktif bermasalah/ non performing asset dibandingkan dengan aktiva produktif

d. Tingkat kecukupan pembentukkan penyisihan penghapusan aktiva produktif (PPAP)

e. Kecukupan kebijakan dan prosedur aktiva produktif, system kaji ulang (review) internal terhadap aktiva produktif

f. Dokumentasi aktiva produktif

g. Kinerja penanganan aktiva produktif bermasalah

3. Manajemen (Management)

Penilaian dilakukan terhadap komponen sebagai berikut:

a. Manajemen umum

b. Penerapan system manajemen risiko

c. Kepatuhan bank terhadap ketentuan yang berlaku serta komitmen kepada Bank Indonesia dan atau pihak lainnya

d. Net Profit Margin (NPM) 
IHTIYATH Jurnal Manajmen Keuangan Syariah

Vol. 3 No. 2, September 2019

4. Rentabilitas (Earnings)

Penilaian dilakukan terhadap komponen sebagai berikut:

a. Return On Assets (ROA)

b. Return On Equity (ROE)

c. Net Interest Margin (NIM)

d. Biaya Opersional dibandingkan dengan Pendapatan Operasional (BOPO)

e. Perekembangan laba opersional

f. Komposisi portofolio aktiva produktif dan diversifikasi/ pendapatan

g. Penerapan prinsip akuntansi dalam pengakuan pendapatan dan biaya

h. Prospek laba opersional

5. Likuiditas (Liquidity)

Penilaian dilakukan terhadap komponen sebagai berikut:

a. Aktiva likuid kurang dari 1 bulan dibandingkan dengan passive likuid kurang dari 1 bulan

b. I-month Maturity Mismatch Ratio

c. Loan to Deposit Ratio (LDR)

d. Proyeksi cash flow 3 bulan mendatang

e. Ketergantungan pda dana antar bank dan deposan inti

f. Kebijakan dan pengelolaan likuiditas (Assets and Liabilities Management/ ALMA)

g. Kemampuan bank untuk memperoleh akses kepada pasar uang, pasar modal, atau sumber-sumber pendanaan lainnya

h. Stabilitas Dana Pihak Ketiga (DPK)

Bobot dari setiap CAMEL untuk Bank Umum menurut Booklet Perbankan Indonesia (2010:110) adalah sebagai berikut:

1. Permodalan dengan bobot $25 \%$

2. Kualitas Aktiva Produktif dengan bobot $30 \%$

3. Kualitas manajemen dengan bobot $25 \%$

4. Rentabilitas dengan bobot $10 \%$

5. Likuiditas dengan bobot $10 \%$

Unsur-unsur penilaian analisis CAMEL menurut Kasmir (2012:11) yaitu: 
1. Capital (permodalan), penilaian dilakukan dengan menggunakan metode CAR (Capital Adequancy Ratio) yaitu mebandingkan modal terhadap Aktiva Tertimbang Menurut Resiko (ATMR).

Kriteria penilaian Capital Adequancy Ratio (CAR):

\begin{tabular}{cl}
\hline Nilai Kredit & Predikat \\
\hline$>8 \%$ & Sehat \\
$6,5 \%-<7,9 \%$ & Kurang Sehat \\
$<6,49 \%$ & Tidak Sehat \\
\hline
\end{tabular}

2. Assets (Kualitas Aktiva), Penilaian dilakukan dengan menggunakan rasio Kualitas Aktiva Produktif (KAP) yaitu membandingkan Aktiva Produktif yang diklasifikasikan terhadap Total Aktiva Produktif.

\begin{tabular}{cl} 
Kriteria penilaian Kualitas Aktiva Produktif (KAP): \\
\hline Nilai Kredit & Predikat \\
\hline$<10,35 \%$ & Sehat \\
$10,36 \%-12,60 \%$ & Cukup Sehat \\
$12,61 \%-14,85 \%$ & Kurang Sehat \\
$>14,85 \%$ & Tidak Sehat \\
\hline
\end{tabular}

3. Management (manajemen), penilaian dilakukan dengan menggunakan rasio Net Profit Margin yaitu membandingkan Earning After Tax (EAT) terhadap Net Sales (Penjualan Bersih). Kriteria sehat pada kinerja keuangan jika NPM $>30 \%$.

4. Earnig (Rentabilitas), penilaian dilakukan dengan menggunakan rasio Beban Opersional Pendapatan Operasional (BOPO) yaitu membandingkan antara beban operasional terhadap pendapatan operasional.

Kriteria Beban Operasional terhadap Pendapatan Operasional

\begin{tabular}{cl} 
& $(\mathrm{BOPO})$ \\
\hline Nilai Kredit & Predikat \\
\hline$<93,52 \%$ & Sehat \\
$93,52 \%-94,73 \%$ & Cukup Sehat \\
$94,74 \%-95,92 \%$ & Kurang Sehat \\
$>95,92 \%$ & Tidak Sehat \\
\hline
\end{tabular}

5. Liqudity (Likuiditas), penilaian dilakukan dengan menggunakan Loan to Deposito Ratio (LDR) yaitu membandingkan jumlah kredit yang diberikan terhadap dana yang diterima.

Kriteria penilaian Loan to Deposito Ratio (LDR):

\begin{tabular}{cc}
\hline Nilai Kredit & Predikat \\
\hline$<94,75$ & Sehat \\
$94,75 \%-98,75 \%$ & Cukup Sehat \\
$98,76 \%-102,25 \%$ & Kurang Sehat \\
$>102,25 \%$ & Tidak Sehat \\
\hline
\end{tabular}




\section{METODE PENELITIAN}

\subsection{Metode Analisis Data}

1). Metode analisis kuantitatif adalah data yang dapat dinyatakan dalam bentuk angka-angka. Pada penelitian ini data yang diperoleh dari laporan keuangan (neraca dan laba rugi) PT. Bank Mandiri (Persero) Tbk. tahun 2011 - 2015

2). Metode analisis kualitatif adalah data yang disajikan dalam bentuk kata-kata yang mengandung makna. Pada penelitian ini data yang diperoleh berupa sejarah dan produk-produk PT.Bank Mandiri (Persero), Tbk.

\subsection{Peralatan Analisis}

Peralatan analisis yang digunakan untuk menganalisis kinerja keuangan berdasarkan rasio profitabilitas berupa Return On Assets (ROA) dan rasio Capital, Assets, Management, Earning and Liqudity (CAMEL).

\section{HASIL DAN PEMBAHASAN}

\subsection{Hasil Penelitian}

Tabel 1.

Hasil Analisis Kinerja Keuangan Berdasarkan Return On Asset (ROA)

\begin{tabular}{ccc}
\hline \multirow{2}{*}{ Tahun } & \multicolumn{2}{c}{ Profitabilitas } \\
\cline { 2 - 3 } & ROA & $\begin{array}{c}\text { Kriteria } \\
\mathbf{1}, \mathbf{2 1 5} \%\end{array}$ \\
\hline $\mathbf{2 0 1 1}$ & $3,37 \%$ & Sehat \\
$\mathbf{2 0 1 2}$ & $3,55 \%$ & Sehat \\
$\mathbf{2 0 1 3}$ & $3,66 \%$ & Sehat \\
$\mathbf{2 0 1 4}$ & $3,57 \%$ & Sehat \\
$\mathbf{2 0 1 5}$ & $3,15 \%$ & Sehat \\
\hline
\end{tabular}

Sumber: Laporan Keuangan Bank diolah

Hasil perhitungan nilai ROA (Return On Asset) PT. Bank Mandiri (Persero) Tbk. pada tahun 2011, 2012, 2013, 2014dan 2015 sebesar 3,37\%, 3,55\%, 3,66\%, 3,57\% dan 3,15\% dikategorikan SEHAT, karena besarnya angka yang diperoleh di atas dari standard kriteria sehat untuk ROA yang telah ditetapkan sebesar 1,215\% 
Tabel 2.

Hasil Analisis Kinerja Keuangan Berdasarkan CAMEL

\begin{tabular}{ccccccccccc}
\hline & \multicolumn{2}{c}{$\boldsymbol{C A P I T A L}$} & \multicolumn{2}{c}{ ASSET } & MANAGEMENT & EARNING & LIQUIDITY \\
\cline { 2 - 4 } Tahn & CAR & $\begin{array}{c}\text { Kriteria } \\
>8 \%\end{array}$ & KAP & $\begin{array}{c}\text { Kriteria } \\
<10,35 \%\end{array}$ & NPM & $\begin{array}{c}\text { Kriteria }> \\
30 \%\end{array}$ & BOPO & $\begin{array}{c}\text { Kriteria } \\
<93,52 \%\end{array}$ & $\begin{array}{c}\text { LDR } \\
<94,75 \%\end{array}$ \\
\hline $\mathbf{2 0 1 1}$ & $15,43 \%$ & Sehat & $1,43 \%$ & Sehat & $58,3 \%$ & Sehat & $67,22 \%$ & Sehat & $71,65 \%$ & Sehat \\
$\mathbf{2 0 1 2}$ & $15,48 \%$ & Sehat & $1,17 \%$ & Sehat & $59,0 \%$ & Sehat & $63,93 \%$ & Sehat & $77,66 \%$ & Sehat \\
$\mathbf{2 0 1 3}$ & $14,93 \%$ & Sehat & $1,17 \%$ & Sehat & $54,9 \%$ & Sehat & $62,41 \%$ & Sehat & $82,97 \%$ & Sehat \\
$\mathbf{2 0 1 4}$ & $16,60 \%$ & Sehat & $1,15 \%$ & Sehat & $54,9 \%$ & Sehat & $64,98 \%$ & Sehat & $82,02 \%$ & Sehat \\
$\mathbf{2 0 1 5}$ & $18,60 \%$ & Sehat & $1,56 \%$ & Sehat & $45,1 \%$ & Sehat & $69,67 \%$ & Sehat & $87,05 \%$ & Sehat \\
\hline
\end{tabular}

Sumber: Laporan Keuangan Bank diolah

1). Hasil perhitungan nilai CAR (Capital Adequency Ratio) PT. Bank Mandiri (Persero), Tbk. pada tahun 2011, 2012, 2013, 2014 dan 2015 sebesar 15,43\%, 15,48\%, 14,93\%, $16,60 \%$ dan 18,60\% dikategorikan SEHAT, karena besarnya angka yang diperoleh di atas dari standard kriteria sehat untuk rasio CAR yang telah ditetapkan sebesar $8 \%$.

2). Hasil perhitungan KAP (Kualitas Asset Produktif) PT. Bank Mandiri (Persero), Tbk. pada tahun 2011, 2012, 2013, 2014 dan 2015 sebesar 1,43\%, 1,17\%, 1,17\%, 1,15\% dan $1,56 \%$ dikategorikan SEHAT, karena besarnya angka yang diperoleh di bawah dari standard criteria sehat untuk rasio KAP yang telah ditetapkan sebesar 10,35\%.

3). Hasil perhitungan NPM ( Net Profit Margin) PT. Bank Mandiri (Persero), Tbk. pada tahun 2011, 2012, 2013, 2014 dan 2015 sebesar 58,3\%, 59,0\%, 54,9\%, 54,9\% dan $45,1 \%$ dikategorikan SEHAT, karena besarnya angka yang diperoleh di atas dari standard criteria sehat untuk rasio NPM yang telah ditetapkan sebesar 30\%.

4). Hasil perhitungan BOPO (Beban Operasional terhadap Pendapatan Operasional) PT. Bank Mandiri (Persero), Tbk. pada tahun 2011, 2012, 2013, 2014 dan 2015 sebesar $67,22 \%, 63,93 \%, 62,91 \%, 64,98 \%$ dan $69,67 \%$ dikategorikan SEHAT, karena besarnya angka yang diperoleh di bawah dari standar criteria sehat untuk rasio BOPO yang telah ditetapkan sebesar 93,52\%.

5). Hasil perhitungan LDR ( Loan to Deposit Ratio) PT. Bank Mandiri (Persero) Tbk. pada tahun 2011, 2012, 2013, 2014 dan 2015 sebesar 71,65\%, 77,66\%, 82,97\%, $82,02 \%$ dan $87,05 \%$ dikategorikan SEHAT, karena besarnya angka yang diperoleh di bawah dari standard criteria sehat untuk LDR yang telah ditetapkan sebesar 94,75\%.

\section{PEMBAHASAN}

1). Kinerja keuangan PT. Bank Mandiri (Persero) Tbk. berdasarkan ROA (Return On Asset) tergolong kriteria sehat, dibuktikan besarnya angka yang diperoleh setiap tahunnya lebih besar dari 1,215\% sesuai dengan kriteria yang ditetapkan oleh BI. Pada tahun 2011 - 2013 ROA mengalami kenaikan, yang menunjukkan bahwa semakin besar ROA suatu bank maka semakin besar pula tingkat keuntungan yang dicapai oleh 
bank. Sedangkan pada tahun 2014 dan 2015 mengalami penurunan namun masih berada pada kategori sehat karena rasio yang dimiliki lebih besar dari 1,215\%, hal ini disebabkan adanya kebijakan ekonomi di beberapa Negara seperti China dan Amerika Serikat yang berdampak pada turunnya nilai tukar rupiah terhadap US Dollar.

2). Pengukuran Kinerja Keuangan PT. Bank Mandiri (Persero) Tbk. berdasarkan CAMEL:

a. CAR (Capital Adequency Ratio) PT. Bank Mandiri (Persero) Tbk. pada tahun 2011 - 2015 setiap tahunnya mengalami kenaikan dan berada pada kategori sehat, karena rasio yang dimiliki lebih besar dari $8 \%$ sesuai dengan kriteria yang telah ditetapkan oleh BI, artinya bahwa tingkat kecukupan modal bank sudah lebih baik.

b. KAP (Kualitas Aktiva Produktif) PT. Bank Mandiri (Persero) Tbk. pada tahun 2011 - 2015 tergolong kriteria sehat, meskipun setiap tahunnya berfluktuasi tetapi masih di bawah standar yang telah ditetapkan oleh BI yaitu $<10,35 \%$, artinya semakin kecil rasio KAP maka aktiva bermasalah pada bank relatif kecil.

c. NPM (Net Profit Margin) PT. Bank Mandiri (Persero), Tbk. pada tahun 2011-2015 setiap tahunnya mengalami fluktuasi, tetapi masih digolongkan pada kriteria sehat karena hasil setiap tahunnya $>30 \%$.

d. BOPO (Beban Operasi Pendapatan Operasi) PT. Bank Mandiri (Persero) Tbk. pada tahun 2011 - 2015 termasuk pada kriteria sehat, karena rasio yang dimiliki lebih kecil dari 93,52\% sesuai dengan ketetapan BI. semakin kecil rasio BOPO maka semakin efisien untuk bank dalam melakukan kegiatan operasional.

e. LDR (Loan to Deposit Ratio) PT. Bank Mandiri (Persero) Tbk. pada tahun 2011 2015 termasuk kriteria sehat, karena lebih kecil dari 94,75\% sesuai dengan standar ketetapan BI. Hal ini menunjukkan tingkat kemampuan bank dalam membayar kembali penarikan dana yang dilakukan oleh deposan

\section{KESIMPULAN}

1). Kinerja keuangan PT. Bank Mandiri (Persero) Tbk. tahun 2011-2015 berdasarkan ROA (Return On Asset) masuk ke dalam kriteria SEHAT, dibuktikan dengan angka rasio yang dihasilkan setiap tahun $>1,215 \%$, artinya bank mampu mengelola asset untuk meningkatkan keuntungan sehingga dapat memberikan pengembalian kepada penanam modal, semakin besar ROA suatu bank maka semakin besar pula tingkat keuntungan yang dicapai oleh bank.

2). Hasil analisis kinerja keuangan dengan menggunakan metode CAMEL, PT. Bank Mandiri (Persero) Tbk. tahun 2011 - 2015 tergolong perusahaan perbankan yang berpredikat SEHAT, dibuktikan dengan angka rasio yang diperoleh setiap tahun dari:

a. CAR $>8 \%$, menunjukkan bahwa bank memiliki modal yang cukup untuk menu- 
tup segala risiko yang mungkin timbul dari penanaman aktiva-aktiva produktif yang mengandung resiko serta untuk membiayai penanaman dana dalam aktiva tetap dan inventaris.

b. KAP $<10,35 \%$, menunjukkan bahwa bank memiliki kualitas asset yang baik sehubungan dengan rasiko kredit yang dihadapi bank akibat pemberian kredit dan aktiva produktif yang diklasifikasikan

c. NPM $>3 \%$, menunjukkan bahwa kemampuan bank dalam menghasilkan laba bersih setelah pajak (Net Income) ditinjau dari sudut pendapatan bersihnya

d. BOPO $<93,52 \%$, menunjukkan bahwa bank sudah efisien dalam pembiayaan opersionalnya.

e. LDR $<94,75 \%$, menunjukkan bahwa bank mampu membayar kembali penarikan dana yang dilakukan oleh deposan.

3). PT. Bank Mandiri (Persero) Tbk. harus bisa meningkatkan angka pada rasio ROA (Return On Asset) ditahun yang akan datang agar dapat menarik para pemegang saham untuk menanamkan modalnya, sehingga bank mampu meningkatkan keuntungan dari pengelolaan asset yang dimiliki.

4). Kinerja keuangan berdasarkan metode CAMEL, khususnya likuiditas diharapkan PT. Bank Mandiri (Persero) Tbk. dapat menurunkan angka pada LDR (Loan to Deposit Rasio) , jika angka yang diperoleh terus mengalami kenaikan setiap tahunnya akan membahayakan kelancaran dalam pembayaran kembali penarikan dana yang dilakukan deposan. Hal ini akan berdampak buruk pada kepercayaan investor untuk menanamkan modalnya ke bank.

\section{DAFTAR PUSTAKA}

Bank Indonesia, 2010, Booklet Perbankan Indonesia, Penerbit: Bank Indonesia, Jakarta.

Fahmi Irham, 2012, Manajemen Keuangan, Aflabeta, Bandung.

Jumingan, 2011, Analisa Laporan Keuangan, PT. Bumi Aksara, Jakarta.

Kasmir 2011, Manajemen Perbankan, PT. Raja Grafindo Persada, Jakarta

Kasmir, 2012, Bank dan Lembaga Keuangan Lainnya, PT. Raja Grafindo Persada, Jakarta

Keown, Arthur J, David F Scot, Jr, John D. Martin dan J. William Petty, 2010, Dasar-Dasar Manajemen Keuangan, Salemba Empat, Jakarta

Noor, Juliansyah, 2014, Analisis Data Penelitian Ekonomi dan Manajemen, Grasindo, Jakarta. 
IHTIYATH Jurnal Manajmen Keuangan Syariah

Vol. 3 No. 2, September 2019

Rivai, Veithzal, 2013, Manajemen Perbankan dari Teori ke Praktik, Rajawali Pers, Jakarta.

Rumondor, Risca Fransiska, 2013, Perbandingan Kinerja Keuangan Bank Mandiri, BRI, dan BNI yang terdaftar di Bursa Efek Indonesia, Jurnal EMBA, Vol.1, No.3, Hal $782-792$.

Surat Edaran Bank Indonesia No. 6/23/DPNP, tanggal 31 Mei 2004 tentang Sistem Penilaian Tingkat Kesehatan Bank Umum.

Syamsuddin, Lukman, 2009, Manajemen Keuangan Perusahaan: Konsep Aplikasi dalam Perencanaan, Pengawasan dan Pengambilan Keputusan, PT. Raja Grafindo Persada, Jakarta.

Undang-Undang No.10 Tahun 1998, tentang Perubahan Undang-Undang No.7 tahun 1992 tentang Perbankan.

www.idx.co.id 